University of South Florida

DIGITAL COMMONS

Digital Commons @ University of

@ UNIVERSITY OF SOUTH FLORIDA

South Florida

6-1992

\title{
The 26-Day Oscillation Observed in the Satellite Sea Surface Temperature Measurements in the Equatorial Western Indian Ocean
}

Pedro T. H. Tsai

James J. O'Brien

Mark E. Luther

University of South Florida, mluther@usf.edu

Follow this and additional works at: https://digitalcommons.usf.edu/msc_facpub

Part of the Life Sciences Commons

\section{Scholar Commons Citation}

Tsai, Pedro T. H.; O'Brien, James J.; and Luther, Mark E., "The 26-Day Oscillation Observed in the Satellite Sea Surface Temperature Measurements in the Equatorial Western Indian Ocean" (1992). Marine Science Faculty Publications. 494.

https://digitalcommons.usf.edu/msc_facpub/494

This Article is brought to you for free and open access by the College of Marine Science at Digital Commons @ University of South Florida. It has been accepted for inclusion in Marine Science Faculty Publications by an authorized administrator of Digital Commons @ University of South Florida. For more information, please contact digitalcommons@usf.edu. 


\title{
The 26-Day Oscillation Observed in the Satellite Sea Surface Temperature Measurements in the Equatorial Western Indian Ocean
}

\author{
Pedro T. H. Tsai, ' James J. O’Brien, And Mark E. Luther ${ }^{2}$ \\ Mesoscale Air-Sea Interaction Group, Florida State University, Tallahassee
}

\begin{abstract}
A 26-day oscillation in sea surface temperature (SST) data is observed in the western Indian Ocean, from $52^{\circ}$ to $60^{\circ} \mathrm{E}$ and in the vicinity of the equator. The SST data used in this study are obtained from the NOAA 9 satellite and are for the years 1987 and 1988. This fluctuation of SST at a period near 26 days is found to be antisymmetric about the equator and is trapped within the equatorial waveguide (equator $\pm 6^{\circ}$ ). The variance associated with this oscillation has a maximum located at about $3^{\circ}$ latitude; furthermore, the variance decreases at a faster rate toward the equator than poleward. These characteristics are consistent with the latitudinal structure for the mixed Rossby-gravity (or Yanai) waves as predicted from linear wave theory. The temporal variation of this 26-day oscillation is most energetic during the summer season (July to September), with maximum values of $0.4^{\circ} \mathrm{C}$ and $0.8^{\circ} \mathrm{C}$ found during August of 1987 and 1988 respectively. This observation agrees with the temporal variation of Yanai waves inferred from drifting buoy observations and numerical studies of the Indian Ocean. Thus we conclude that the Yanai wave is responsible for the 26-day fluctuation observed in the SST data in this region.
\end{abstract}

\section{INTRODUCTION}

The investigation of equatorially trapped waves has been an active area of ongoing study in the last two and a half decades. This is, in part, because these waves are of major importance in the problem of equatorial ocean adjustment to unsteady wind forcing. On the basis of the dispersion relations derived from the linear wave theory, these waves are classified as the Kelvin wave, the Rossby wave, the inertiagravity wave, and the mixed Rossby-gravity wave (or Yanai wave) [Moore and Philander, 1977]. Evidence for these waves have been observed in satellite measurements of sea surface temperature [Legeckis, 1977], in sea level records from islands in the equatorial Pacific Ocean [Wunsch and Gill, 1976], in data from moored current meters [Knox and Halpern, 1982], and in many other studies.

Among the various types of equatorially trapped waves, the Yanai wave is unusual because it has no counterpart at higher latitudes. The Yanai wave and the Kelvin wave arise because the Coriolis acceleration changes sign at the equator. In the Indian Ocean the Yanai wave was first observed by Luyten and Roemmich [1982]. They examined current measurements in the western equatorial Indian Ocean at $55^{\circ} \mathrm{E}$ longitude and found a prominent 26-day oscillation in the record of the meridional velocity in the upper $200 \mathrm{~m}$. Interestingly, no corresponding peak near the same period is found in the spectrum of the zonal velocity. The zonal wavelength of this oscillation is estimated to be approximately $800-1000 \mathrm{~km}$, with meridional velocity of $0.15 \mathrm{~m} \mathrm{~s}^{-1}$ to $0.3 \mathrm{~m} \mathrm{~s}^{-1}$. In addition, this oscillation exhibits a westward phase propagation, with eastward and downward energy propagation. These characteristics suggest that the 26-day

\footnotetext{
${ }^{1}$ Now at Department of Oceanography, Naval Postgraduate School, Monterey, California.

${ }^{2}$ Now at Department of Marine Science, University of South Florida, St. Petersburg.

Copyright 1992 by the American Geophysical Union.

Paper number 91JC03162.

0148-0227/92/91JC-03162\$05.00
}

oscillations which they found are a result of propagating Yanai waves. In a later investigation, Reverdin and Luyten [1986] examined the data obtained from drifting buoys that were released along the equator in the western Indian Ocean between $50^{\circ} \mathrm{E}$ and $60^{\circ} \mathrm{E}$ from 1979 to 1982 . They concluded that the meandering behavior exhibited by the drifting buoys was associated with the motions of the Yanai waves.

A possible source of these 26-day Yanai waves is the western boundary [Kindle and Thompson, 1989; Moore and McCreary, 1990; Woodberry et al., 1989]. Using a linear, continuously stratified model, Moore and McCreary have shown that application of a periodic wind stress along a slanted coastline (like that of the Indian Ocean) excites equatorially trapped waves. By varying the frequency of the oscillating wind forcing along the western boundary, different equatorially trapped waves are generated. For example, for a 30-day period, only the Yanai wave and the Kelvin wave are excited, whereas for a 60-day period, Rossby waves are also excited.

A different generating mechanism is described by Kindle and Thompson [1989]. They use a nonlinear, reduced gravity model with a realistic geometry of the Indian Ocean basin. This model is forced with climatological monthly mean winds of Hellerman and Rosenstein [1983]. Yanai waves with a period of 26 days were observed in their model simulations: the model shows that these waves are formed within $1400 \mathrm{~km}$ of the western boundary, with the initial group of wave packets generated during late July-August. Kindle and Thompson [1989, p. 4730] attributed the generation of these 26-day Yanai waves to "instability associated with the circulation of the southern gyre during the latter stages of the southwest monsoon."

Yanai waves were also found in the Indian Ocean modeling by Woodberry et al. [1989]. In the time versus longitude plot of meridional transport across the equator [Woodberry et al., 1989], packets of wave energy with westward phase speed (about $0.2 \mathrm{~m} \mathrm{~s}^{-1}$ ), and eastward group propagation (about $0.24 \mathrm{~m} \mathrm{~s}^{-1}$ ), can be seen emanating from the western boundary region. These waves have a period of 28 days and are interpreted as Yanai waves. The strongest and most 
coherent signals of these waves are seen in the region between $50^{\circ} \mathrm{E}$ and $65^{\circ} \mathrm{E}$, during July, August and September.

The results from both the numerical simulations and from observations support the existence of the Yanai wave in the western Indian Ocean. This is the main motivation for our study of the satellite-derived sea surface temperature (SST) measurements in this region. In the present analysis, we are interested in detecting the signal of the equatorially trapped waves in the fluctuation of SST data. For example, a downwelling Kelvin wave traveling along the equator will depress the thermocline; consequently, the mixed layer becomes deeper and an anomalously warm surface water is formed. Hence changes in SST are indicative of vertical motions of the thermocline, which in turn can be related to the motion of propagating internal waves.

A simple linear wave model is used in this study to explain the observed fluctuation in the SST data. It should be pointed out that fluctuations in the SST involve both dynamic and thermodynamic processes. Our linear model is a purely dynamical model and does not include effects such as evaporative cooling, mixing, etc. The purpose here is not to explain all the physics affecting the SST, but rather to show that a part of the fluctuations in the SST data is caused by the equatorially trapped waves.

In the next section, a description of the large-scale circulation pattern in the western Indian Ocean as revealed from the satellite SST imagery is given. In section 3, characteristics of the equatorially trapped waves are discussed in the context of linear wave theory. In section 4 we will show that 26-day oscillation found in the SST data can be attributed to the Yanai wave. The seasonal and interannual variability of this wave are also investigated. In the last section we will summarize and discuss the results.

\section{DAtA}

\subsection{Source}

The data used for this study are the multichannel sea surface temperature (MCSST) obtained from the advanced very high resolution radiometer (AVHRR) carried on board the NOAA 9 satellite. In the MCSST method, radiation emitted from the sea surface in the visible and several infrared (IR) regions is measured (AVHRR scans five frequency bands: visible, $0.58-0.68 \mu \mathrm{m}$; visible/near IR, 0.725$1.1 \mu \mathrm{m}$; short-wavelength IR, 3.55-3.93 $\mu \mathrm{m}$; and two longwavelength IR bands, 10.3-11.3 $\mu \mathrm{m}$ and 11.5-12.5 $\mu \mathrm{m})$. By comparing the measurements from different channels, tests can be made to detect presence of clouds and determine atmospheric attenuation (see McMillin and Crosby [1984] for a complete discussion on this method). This enables the raw data to be screened for clouds, and only the remaining measurements, corrected for atmospheric effects, were used in the final production of SST fields. Global statistical measure of MCSST data relative to drifting buoys yielded consistent biases (buoy minus satellite) near $-0.1^{\circ} \mathrm{C}[\mathrm{Mc}$ Clain et al., 1985]. A total of 730 data sets were available, one for each day of 1987 and 1988 . For each data set, the temperature resolution is $0.125^{\circ} \mathrm{C}$ and the spatial resolution is about $55 \mathrm{~km}$ (half a degree) in both latitude and longitude.

\subsection{Observation}

A chronological description of MCSST data and circulation features revealed from the data is given in this section.
Our emphasis will be on the western Indian Ocean basin and east African coast, since it is here that the most energetic, time-varying current is found, i.e., the Somali Current and its seasonal reversal in response to the summer and winter monsoons. This region is also where the spatial and temporal changes in SST are the most dramatic.

Beginning with the winter monsoon of 1987 (Plate 1), a cold tongue of surface water, with temperatures between $23^{\circ} \mathrm{C}$ and $26^{\circ} \mathrm{C}$, can be seen extending southwestward from the northern Arabian Sea/Gulf of Oman to the Somalia coast. The coldest water $\left(23^{\circ} \mathrm{C}\right)$ is found along the coast of Pakistan from its border with Iran to its border with India. East and south of this cold tongue, the SST gradually increases with warmest water (SST $>29^{\circ} \mathrm{C}$ ) found near the southwest coast of India and in the vicinity of the Maldive Islands. The cold SST along the coast of Oman and in the northern Arabian Sea during the winter monsoon is a result of evaporative cooling from the flow of cold continental air over water and is further enhanced by the entrainment of subsurface water by turbulence generated by surface cooling [McCreary and Kundu, 1989].

From late February to April this cold tongue gradually weakens and moves northward and is replaced by a belt of warm surface water with temperatures between $28^{\circ} \mathrm{C}$ and $31^{\circ} \mathrm{C}$. By late April-early May, during the transition from winter monsoon to summer monsoon, the $29^{\circ} \mathrm{C}$ and warmer SST can be seen over most of the Indian Ocean basin and the Arabian Sea (Plate 2).

Around the beginning of June (Plate 3), the area of above $29^{\circ} \mathrm{C}$ water recedes eastward and northward. Along the Somali coast, cold pockets of surface water can be seen between the equator and the horn of Africa. The formation of these cold pockets can be attributed to the coastal upwelling. This coastal upwelling is a result of the Ekman transport of surface water away from the coast in response to the southwesterly winds [Schott, 1983; Swallow et al., 1983; Knox, 1987]. By late June (Plate 4) and early July (Plate 5), with the onset of the summer monsoon well underway, the intrusion of the upwelled cold water (characterized by temperature of approximately $26^{\circ} \mathrm{C}$ ) into the interior of the western Indian Ocean basin can be seen in both Plates 4 and 5 , in the form of two cold wedges extending offshore from the Somali coast in the vicinity of $5^{\circ} \mathrm{N}$ and $10^{\circ} \mathrm{N}$. These cold wedges appear with regularity and at about the same locations from June to August in the satellite SST imagery.

The appearance of these cold wedges can be associated with the formation of the Great Whirl and the southern gyre [see Brown et al., 1980; Evans and Brown, 1981; Bruce, 1979]. As the Somali Current flows northward along the African coast in response to the southwest monsoon, at certain locations some part of this current branches off and flows away from the coast to form recirculation regions, or eddies [Leetma et al., 1982]. These branching off points can be seen in the satellite SST imagery as advection of cold coastal surface water offshore. The cold wedge near $5^{\circ} \mathrm{N}$ is one of these offshore flows. It forms the boundary that separates the recirculation region to the south, i.e., the southern gyre, from the one to the north known as the Great Whirl. The other cold wedge near $10^{\circ} \mathrm{N}$ and just south of the island of Socotra, seen in Plate 4 and Plate 5, defines the northern wall of the Great Whirl.

By late August the boundary between the southern gyre 


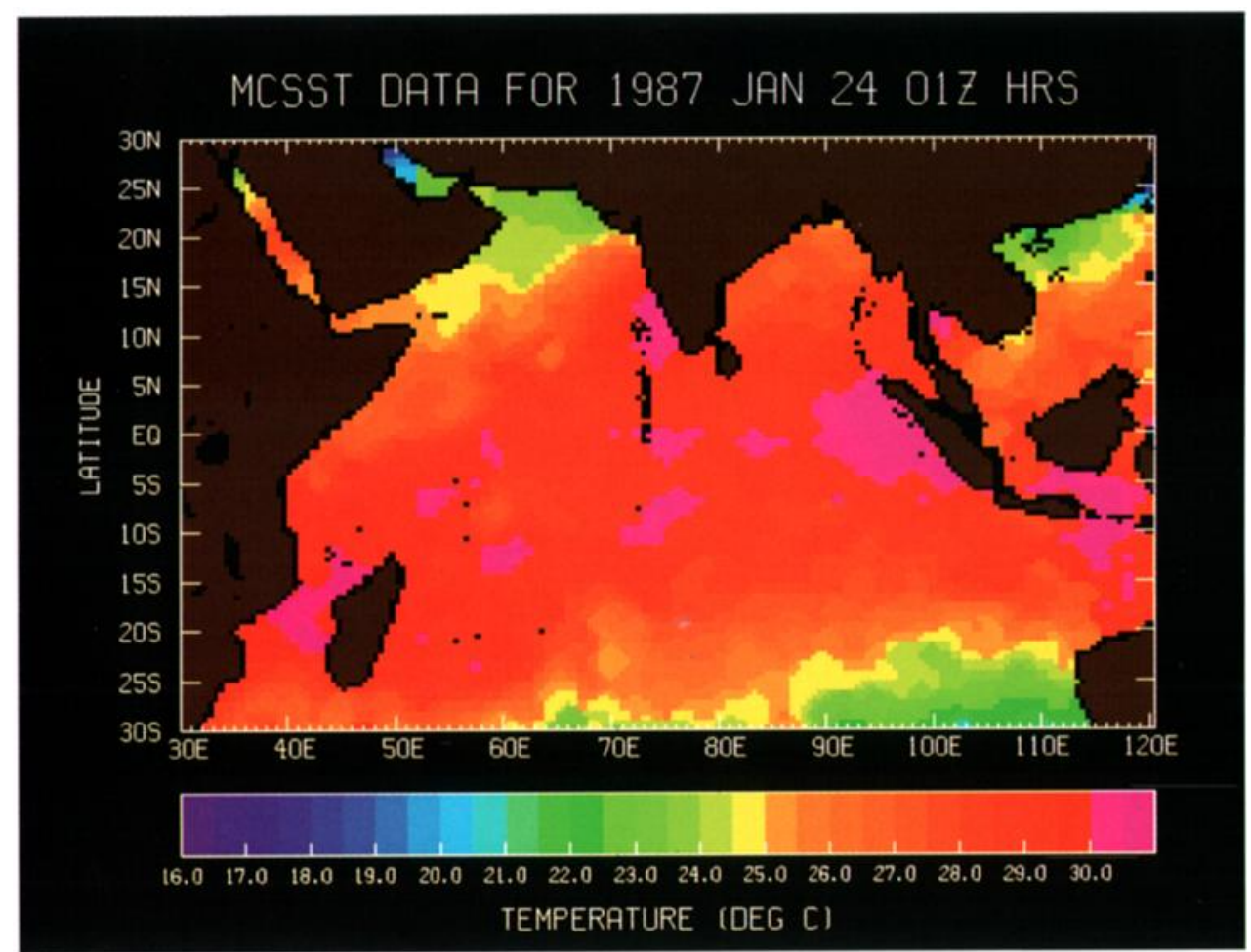

Plate 1. Satellite SST imagery for January 24,1987 . Red color indicates warm SST and blue color, cold SST. The color scale corresponds to temperatures ranging from $16^{\circ} \mathrm{C}$ to $30^{\circ} \mathrm{C}$, with increments of $0.5^{\circ} \mathrm{C}$. The spatial resolution is half of a degree in both latitude and longitude.

and the Great Whirl has become less well defined. Another area of intense upwelling can be seen along the coast of Oman (from $10^{\circ}$ to $20^{\circ} \mathrm{N}$ ) and between $52^{\circ}$ and $60^{\circ} \mathrm{E}$ of the northern Arabian Sea (Plate 6). The upwelling of cold water in this region is attributed to the positive wind stress curl associated with the summer monsoon. This mechanism is different from the one along the Somali coast. The upwelling activity in this region appears to be most vigorous during the

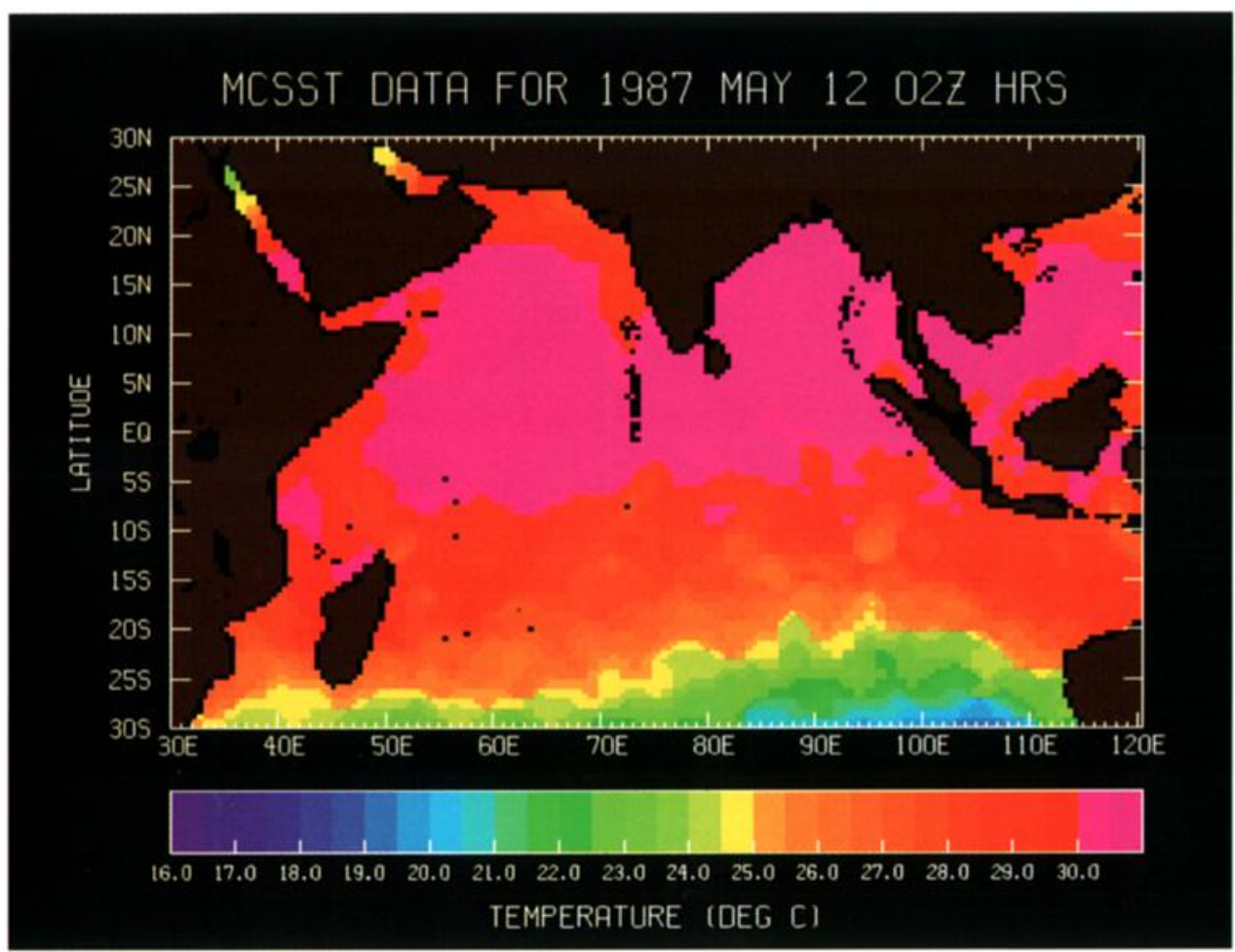

Plate 2. Satellite SST imagery for May 12, 1987. 


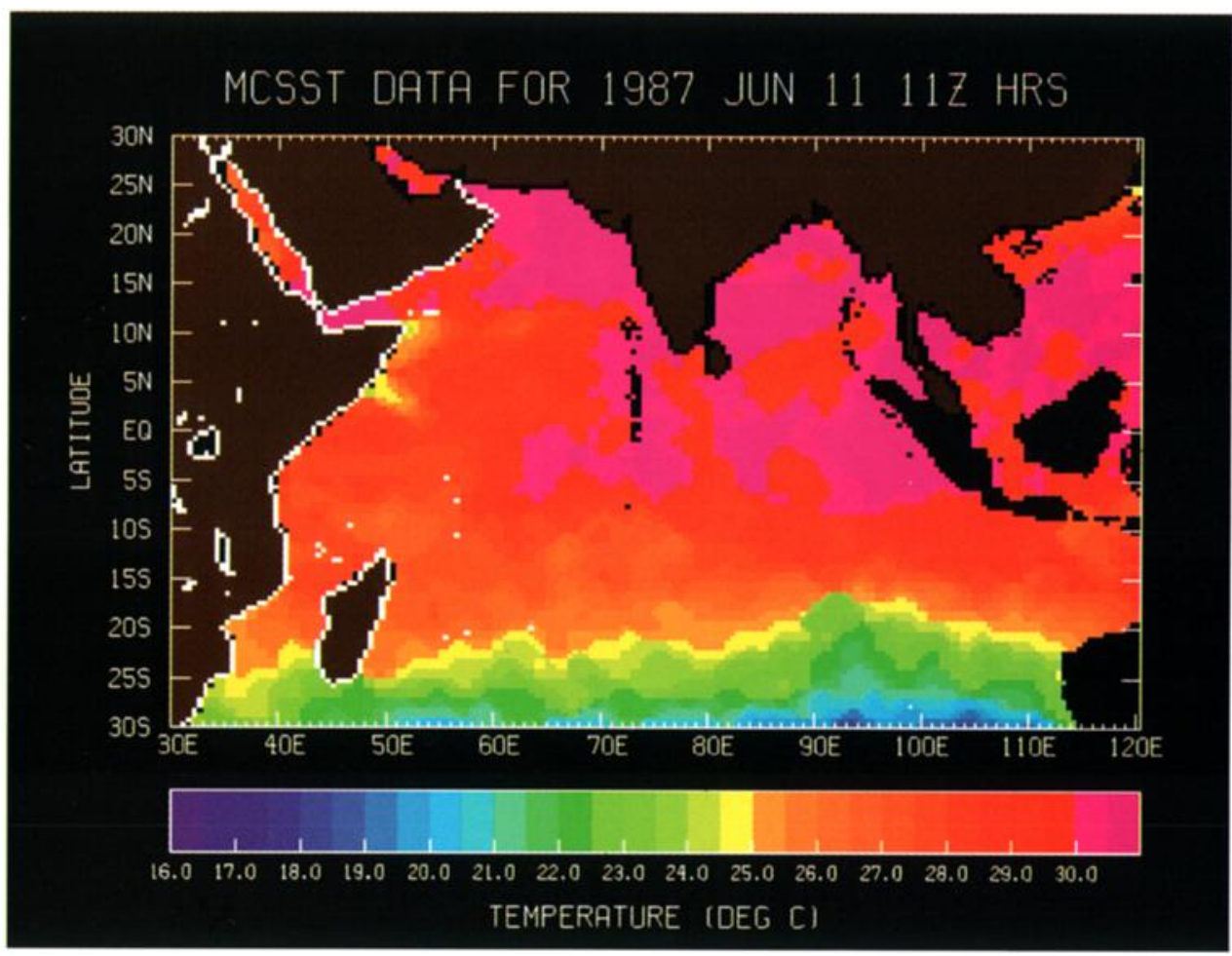

Plate 3. Satellite SST imagery for June 11, 1987.

height of the summer monsoon, as subsequent satellite imagery shows a rapid warming trend after August. This tendency can also be observed in the Climatic Atlas of the Indian Ocean [Hastenrath and Lamb, 1979].

By September (Plate 7), the north wall of the Great Whirl is still visible; however, the cold wedge to the south is no longer resolved in the satellite imagery. This seems to indicate the northward migration of the southern gyre and its subsequent merging with the Great Whirl. The coalescence of the Great Whirl and the southern gyre during the late stage

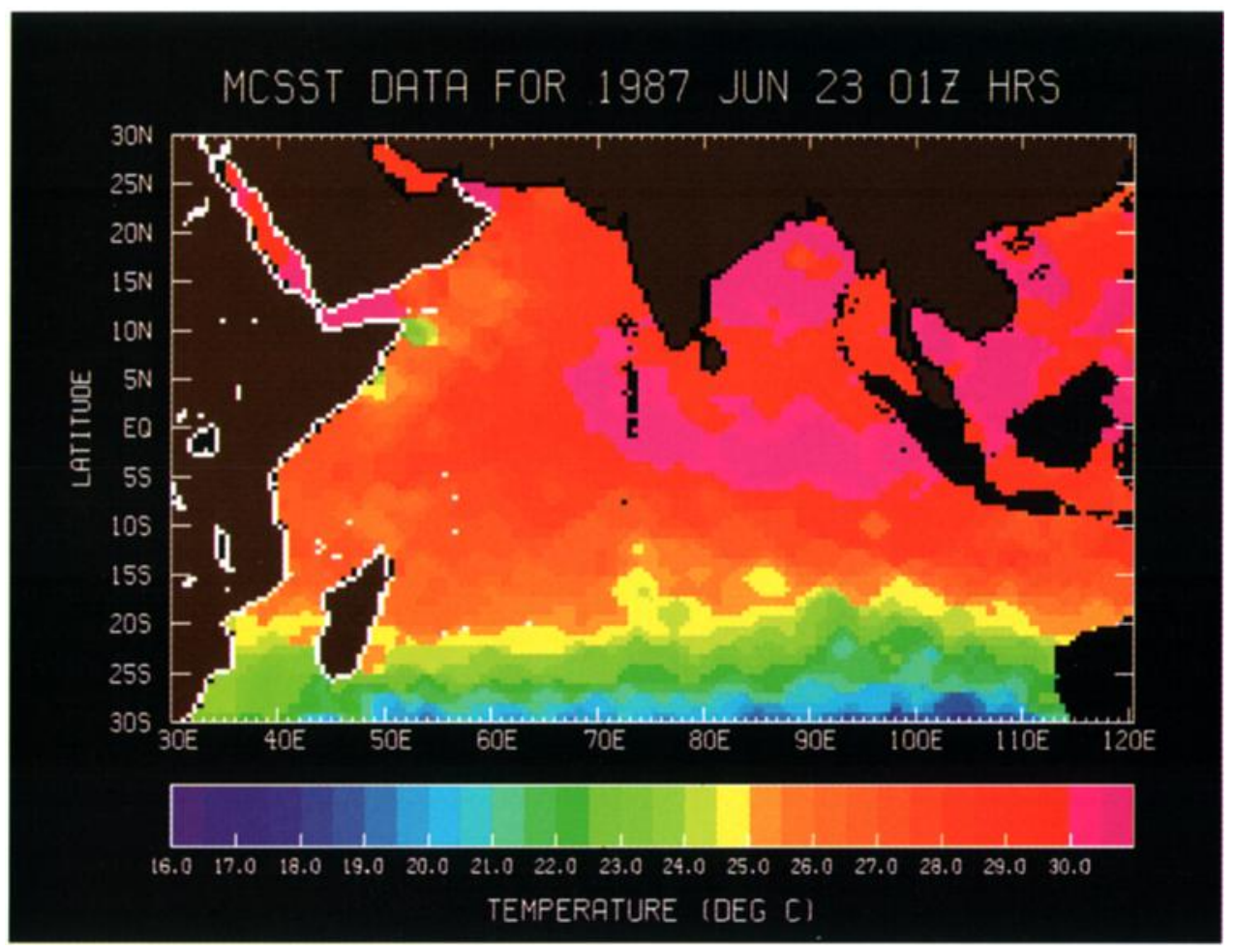

Plate 4. Satellite SST imagery for June 23, 1987. 


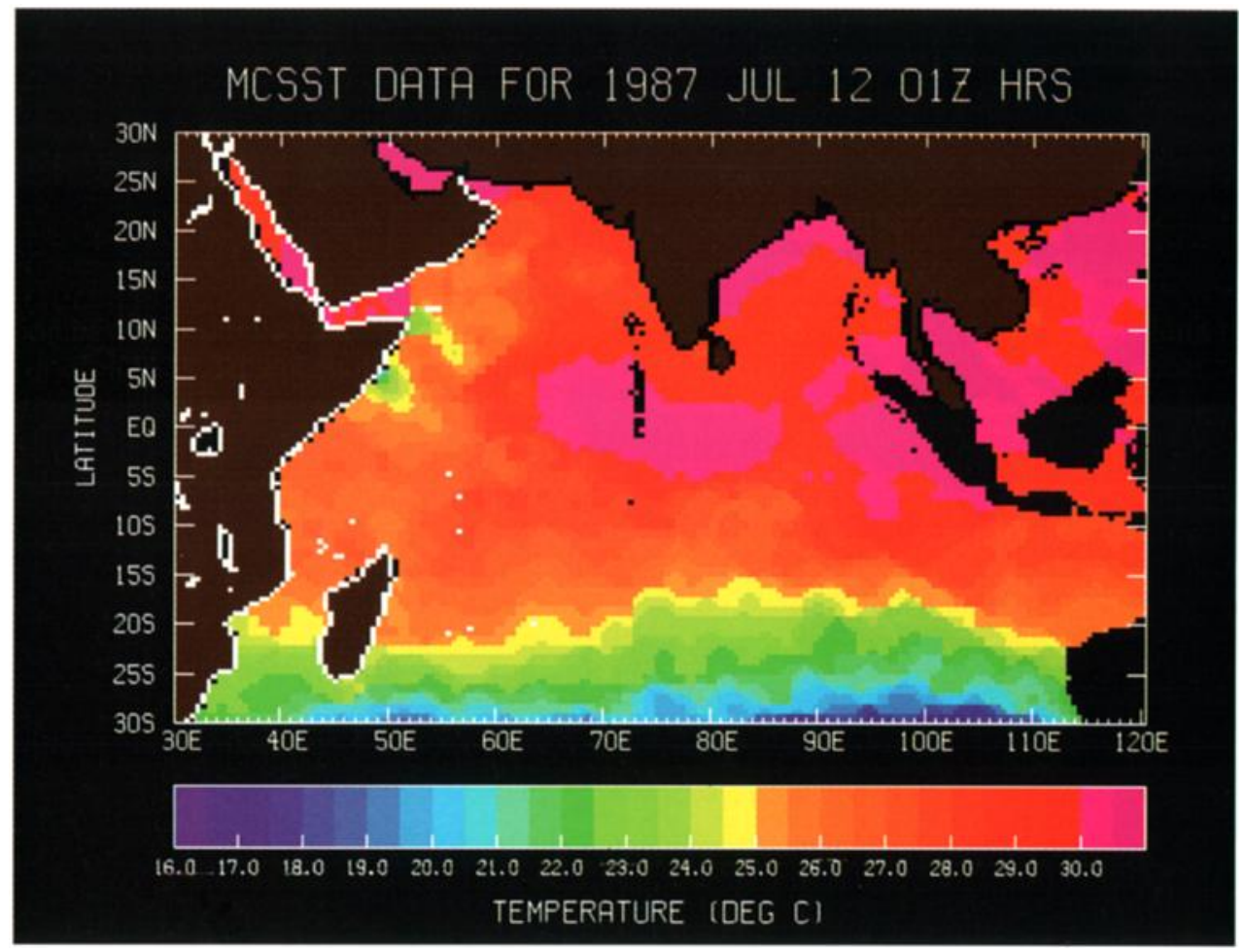

Plate 5. Satellite SST imagery for July 12, 1987.

of summer monsoon has been simulated in the Indian Ocean model by Luther et al. [1985]. This phenomenon is thought to be triggered by the weakening of the westerly component of the near-equatorial wind stress.

From late September to November, warm surface water rapidly replaces the cold upwelling along the Somali coast. This trend persists until early December when the cooling associated with the northeast monsoon begins to take effect, starting with formation of cold SST near Gulf of Oman which then propagates southwestward.

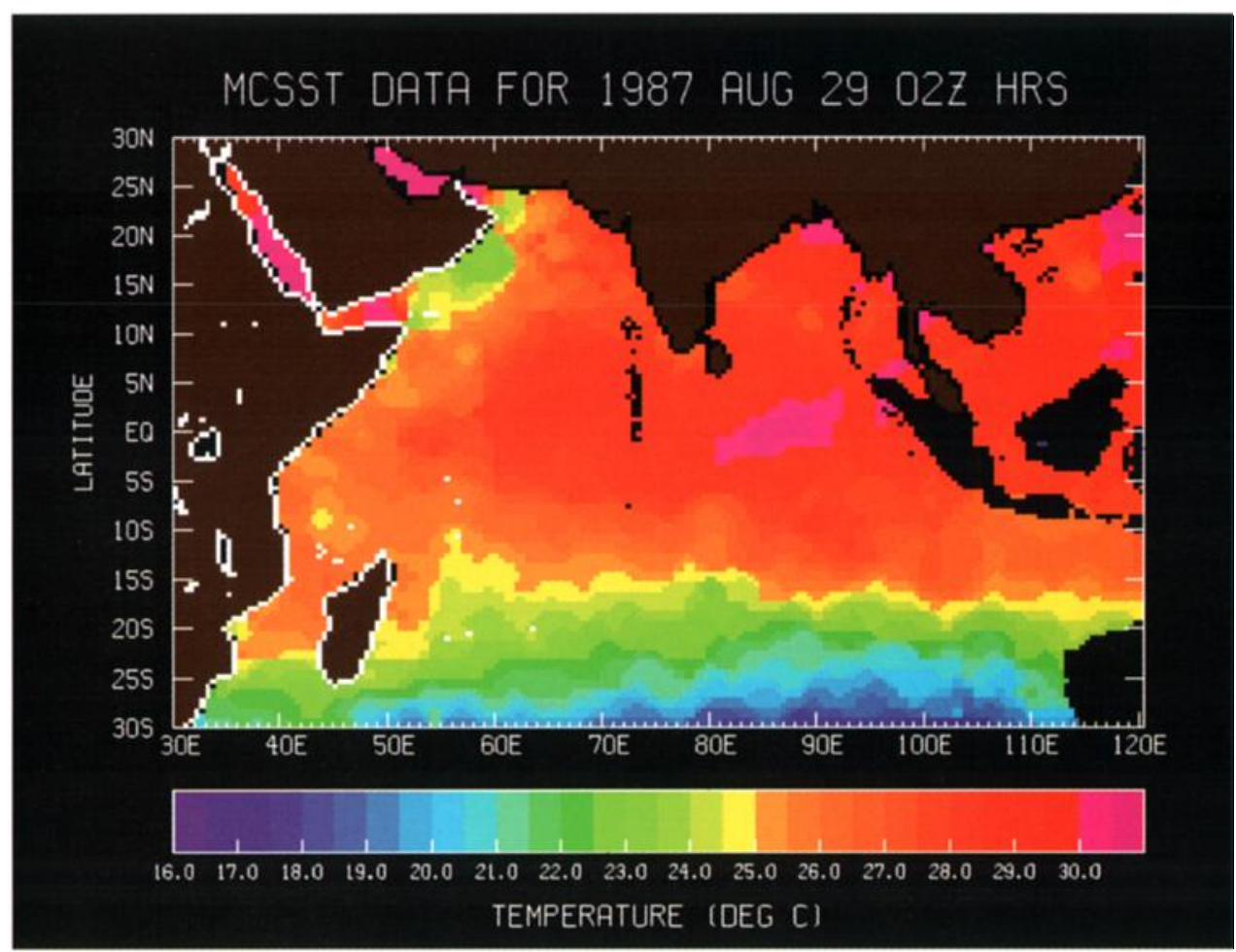

Plate 6. Satellite SST imagery for August 29, 1987. 


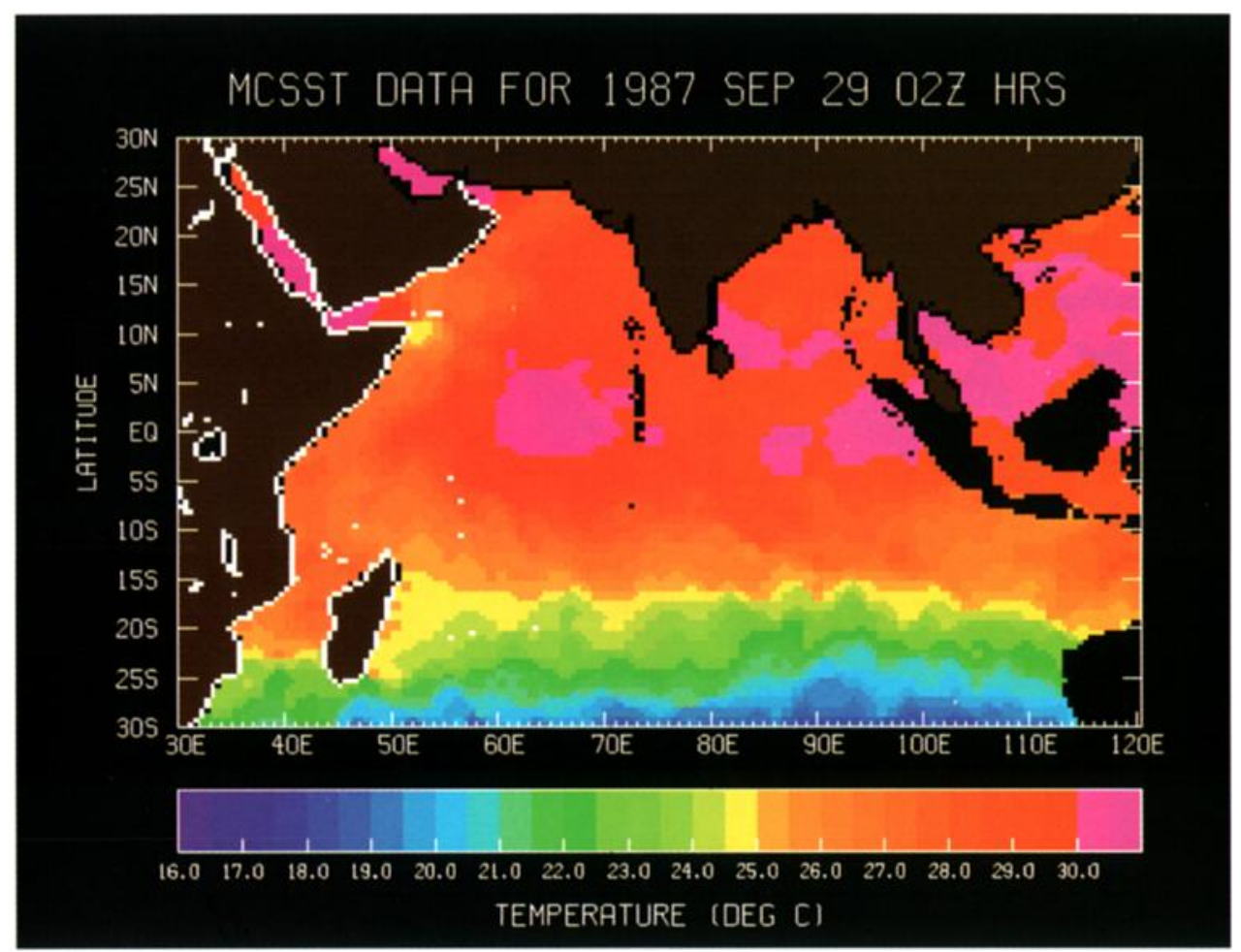

Plate 7. Satellite SST imagery for September 29, 1987.

A similar pattern is revealed in satellite SST imagery for 1988. However, one major difference appears to be the strength of coastal upwelling and the eddy activities during summer. Plate 8 shows the SST imagery for August of 1988. Comparing this with the 1987 data of same time frame, we see that in addition to the two cold wedges described earlier, a third wedge can also be seen to emanate from the east African coast near the equator. This third cold wedge seems to indicate the formation of a large recirculation region in the Somali current near the equator, and appears to be a part of

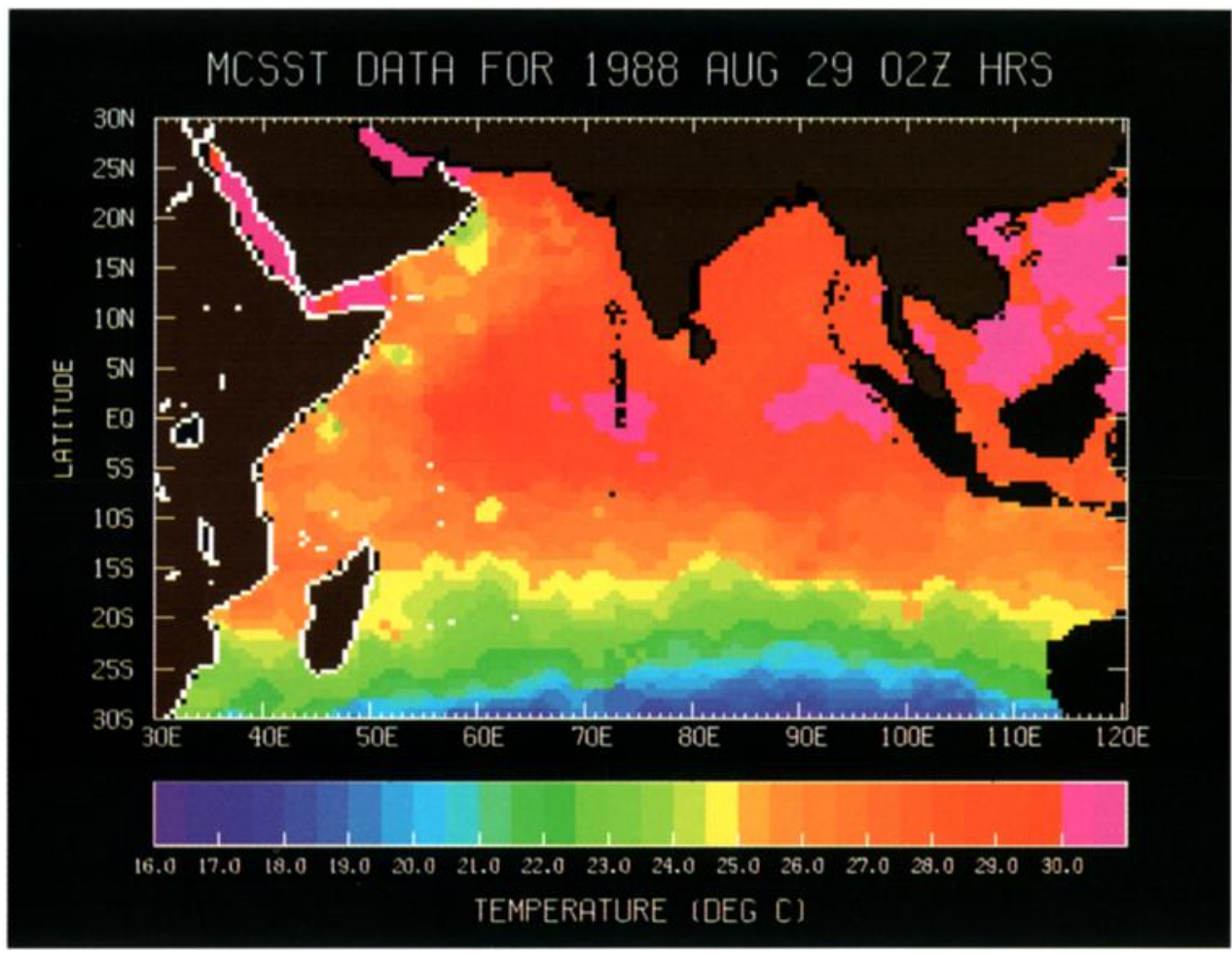

Plate 8. Satellite SST imagery for August 29, 1988. 
the three gyre systems described by Luther et al. [1985]. The size of the upwelling region along the Somali coast also appears to be more extensive in 1988 than in 1987.

\section{Linear Wave Theory}

Solutions to the linear wave theory have been studied by many authors [e.g., Matsuno, 1966; Moore, 1968; Moore and Philander, 1977; Wunsch and Gill, 1976]. Here we will summarize the results from a linear, inviscid, $1 \frac{1}{2}$-layer ocean model on an equatorial $\beta$ plane. We assume no forcing because we are interested in free wave solutions. The momentum equations and conservation of mass equation are (in nondimensional form):

$$
\begin{gathered}
u_{t}-y v=-h_{x} \\
v_{t}+y u=-h_{y} \\
h_{t}+u_{x}+v_{y}=0
\end{gathered}
$$

where $h$ is the deviation of the upper layer depth from its unperturbed depth, $y$ is the distance from the equator (positive northward and negative southward), and $x$ is distance in the east-west direction (increasing toward the east); $u$ is the zonal velocity; and $v$ is the meridional velocity.

Four types of waves are found. One of them, the inertiagravity wave, is a high-frequency gravity wave. It has a typical period of a week or less. Since we are interested in detecting sea surface temperature oscillations that have periods greater than 2 weeks, the inertia-gravity wave is therefore ignored in the subsequent discussion. A description follows of the remaining types of waves found, namely, the Kelvin wave, Yanai wave, and Rossby wave, with emphasis placed on the Yanai wave.

\subsection{Kelvin Wave}

Kelvin waves are nondispersive and have structures that are highly coherent over a large zonal distance within the equatorial waveguide (equator $\pm 300 \mathrm{~km}$ ) [Luther, 1980]. Fluid velocities and height field are given by (in nondimensional form):

$$
\begin{gathered}
v=0 \\
u=h=F(x-t) \exp \left(-y^{2} / 2\right)
\end{gathered}
$$

with dispersion relation $\omega=\kappa$ and group and phase velocity $C_{g}=C_{p}=1$.

Kelvin waves have been observed to travel a long distance along the equator while keeping approximately the same waveform, as may be expected given their nondispersive nature [Knox and Halpern, 1982]. Hurlburt et al. [1976] showed that Kelvin waves are generated by the abrupt change in the zonal wind forcing. For example, in the equatorial Pacific Ocean, these waves are excited by a sudden relaxation or increase of trade winds. Kelvin waves have a symmetric structure about the equator. In addition, because of the requirement of geostrophic balance in the $y$ direction, Kelvin waves can only propagate eastward, with typical phase speeds in the oceans being of the order of $2.0-3.0 \mathrm{~m} \mathrm{~s}^{-1}$. Unlike other equatorial waves, Kelvin waves do not have to be periodic. They can take the form of an impulse function or a disturbance in the equatorial waveguide.

\subsection{Yanai Wave}

Yanai waves behave like Kelvin waves at high frequency and like short Rossby waves at low frequency. The structures of Yanai waves are given by

$$
\begin{gathered}
v=\exp \left(i\left(\omega-\frac{1}{\omega}\right) x-i \omega t\right) \frac{\exp \left(-y^{2} / 2\right)}{\left(p^{1 / 2}\right)^{1 / 2}} \\
u=h=\frac{i \omega}{2^{1 / 2}} \exp \left[i\left(\omega-\frac{1}{\omega}\right) x-i \omega t\right] \frac{\exp \left(-y^{2 / 2}\right) 2 y}{\left(2 p^{1 / 2}\right)^{1 / 2}}
\end{gathered}
$$

with the dispersion relation $\kappa=\omega-(1 / \omega)$ and group and phase velocity given by

$$
C_{g}=\frac{\omega^{2}}{\omega^{2}+1} \quad C_{p}=\frac{\omega^{2}}{\omega^{2}-1}
$$

The group velocity of the Yanai wave is always positive (wave energy propagates eastward), but the phase can travel east or west depending on the frequency. Unlike the Kelvin wave, the Yanai wave is antisymmetric about the equator. The height field of the Yanai waves (Plate 9) is characterized by a series of opposite highs and lows across the equator. This height field (or pressure field) generates flows across the equator which alternate in direction from northbound to southbound every half a zonal wavelength. The meridional extent of this meandering flow is strongly trapped to within two Rossby deformation radii of the equator. At the equator the meridional velocity is at a maximum while zonal velocity is zero.

In the Indian Ocean, Yanai waves with a period of 30 days have a typical zonal wavelength of about $800 \mathrm{~km}$, meridional velocity of $0.1 \mathrm{~m} \mathrm{~s}^{-1}$ to $0.3 \mathrm{~m} \mathrm{~s}^{-1}$, and latitudinal trapping scale of about $750 \mathrm{~km}$ from the equator [Moore and $\mathrm{Mc}$ Creary, 1990]. In addition, fluctuation of $15 \mathrm{~m}$ and more in the thermocline depth and changes in SST of about $1^{\circ} \mathrm{C}$ associated with the activity of the Yanai waves have been observed in data obtained by drifting buoys [Reverdin and Luyten, 1986].

The highs and lows of the height field in Plate 9 can be related to warm and cold sea surface temperatures. A high (low) means thicker (shallower) mixed layer due to convergence (divergence) of water. In the area where convergence (divergence) occurs, the thermocline becomes deeper (shallower) and as a result SST is warmer (colder). Thus it is possible to detect these waves by examining the SST data provided that changes in SST due to convergence/ divergence are sufficiently large compared with the background noise.

\subsection{Rossby Wave}

Rossby waves are the low-frequency planetary waves. They have the same $u, v$, and $h$ as the inertia-gravity waves (see appendix) but with the dispersion relation, group velocity, and phase velocity given by

$$
\begin{gathered}
\omega=\frac{-\kappa}{\kappa^{2}+(2 m+1)} \\
C_{g}=\frac{\kappa^{2}-(2 m+1)}{\left(\kappa^{2}+(2 m+1)\right)^{2}} \\
C_{p}=\frac{-1}{\kappa^{2}+(2 m+1)}
\end{gathered}
$$




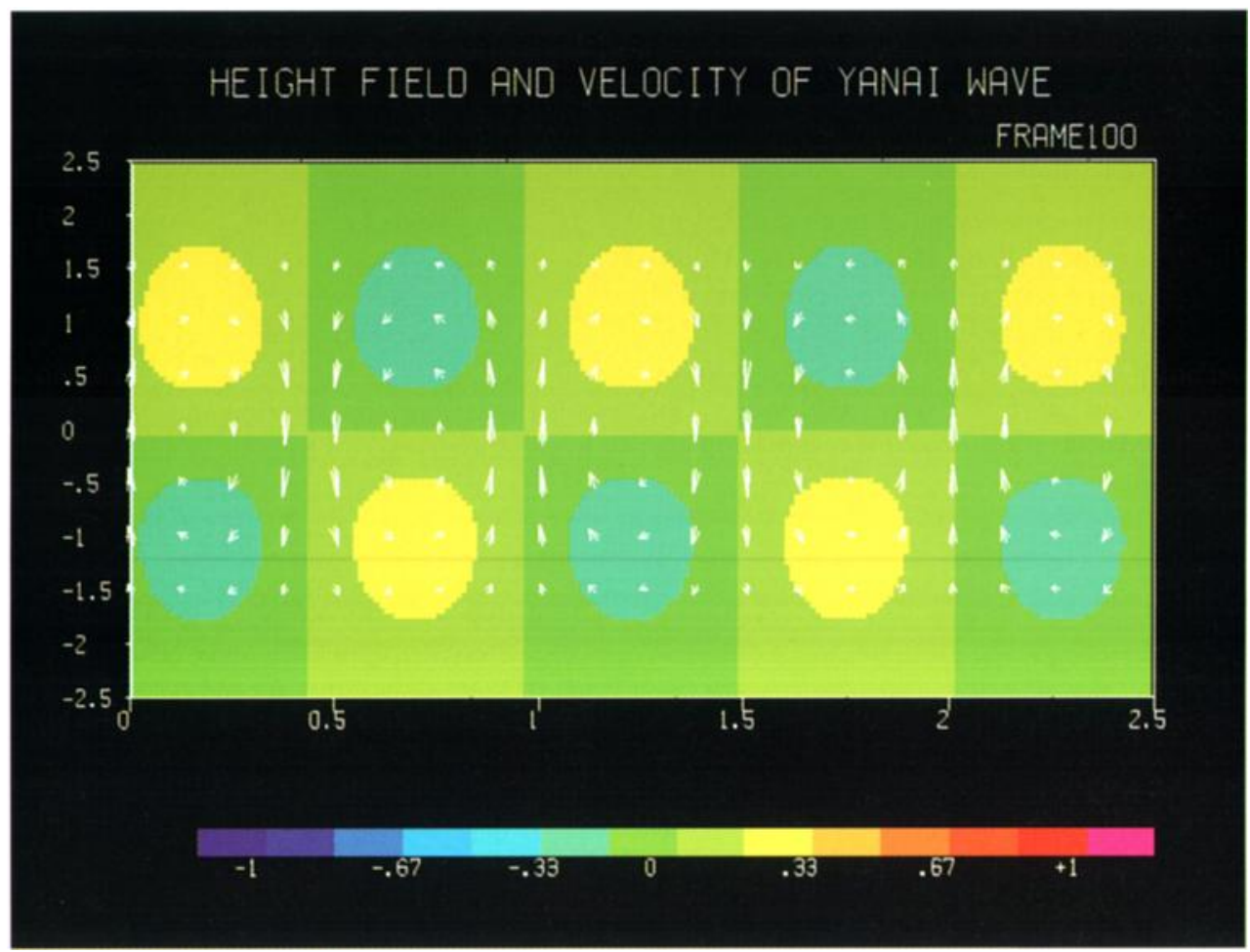

Plate 9. Plot of the velocity and height fields for the freely propagating Yanai wave packets. The unit for the horizontal scale is one zonal wavelength, and for the meridional scale is one Rossby deformation radius, $(c / \beta)^{1 / 2}$.

For a given horizontal mode $m, C_{g}$ is negative (westward energy propagation) for $|\kappa|<(2 m+1)^{1 / 2}$ and positive (eastward energy propagation) for $|\kappa|>(2 m+1)^{1 / 2}$. The former is called the long Rossby wave, while the latter is known as the short Rossby wave. The phase propagation of the Rossby wave is always westward. The latitudinal structures of Rossby wave are described by the Hermite function; thus for even $m$ the Rossby waves are antisymmetric about the equator, and for odd $m$ they are symmetric about the equator.

To obtain dimensional quantities, we multiply nondimensional quantities with scaling factors (prime denotes nondimensional parameters)

$$
\begin{gathered}
(x, y)=(c / \beta)^{1 / 2}\left(x^{\prime}, y^{\prime}\right) \\
\left(u, v, C_{g}, C_{p}\right)=c\left(u^{\prime}, v^{\prime}, C_{g}^{\prime}, C_{p}^{\prime}\right) \\
w=(\beta c)^{1 / 2} \omega^{\prime} \\
k=(\beta / c)^{1 / 2} k^{\prime} \\
t=\frac{1}{(\beta c)^{1 / 2}} t^{\prime} \\
h=H_{0} h^{\prime}
\end{gathered}
$$

where $c$ is the characteristic speed, and the parameter $\beta$ is chosen to be $2.3 \times 10^{-11} \mathrm{~m}^{-1} \mathrm{~s}^{-1}$ for the equatorial region. The characteristic speed $c$ is determined by the stratification of the ocean. In the Indian Ocean, a typical vertical density profile yields a characteristic speed (for second baroclinic mode) of about $1.67 \mathrm{~m} \mathrm{~s}^{-1}$ [Moore and McCreary, 1990]. A simple calculation shows that $(\beta c)^{1 / 2}=0.54 \mathrm{day}^{-1}$ and $(\beta / c)^{1 / 2}=1 / 270 \mathrm{~km}$. Using these scaling parameters, we see from the dispersion diagram (Figure 1), that Rossby waves have periods of about 40 days and more and that inertiagravity waves have periods of approximately 7 days and less. Hence for periods between 1 and 6 weeks, we expect to find only the Yanai and the Kelvin waves.

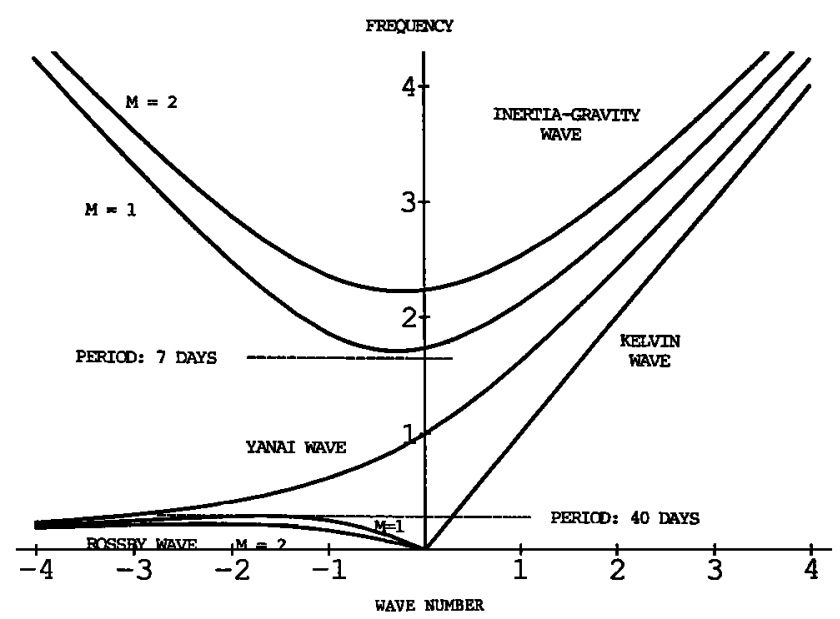

Fig. 1. Dispersion diagram for the equatorial trapped waves. The horizontal-axis is the wave number $\kappa$, with unit of $1 /$ Rossby deformation radius, i.e., $(\beta / c)^{1 / 2}$. The vertical-axis is the frequency $\omega$, with unit of $(\beta c)^{i / 2}$. For $c$ (Kelvin wave speed) $=1.67 \mathrm{~m} \mathrm{~s}^{-1}$ [Moore and McCreary, 1990] and $\beta=2.3 \times 10^{-11} \mathrm{~m}^{-1} \mathrm{~s}^{-1}$, then $(\beta / c)^{1 / 2}=1 / 270 \mathrm{~km}$ and $(\beta c)^{1 / 2}=0.54 \mathrm{day}^{-1}$. From the dispersion diagram, we expect to find only the Yanai and the Kelvin waves for periods between 1 and 6 weeks. 


\section{Results}

\subsection{The 26-Day Oscillation in the Equatorial Waveguide}

From the linear wave theory, equatorial-trapped waves such as Yanai wave and even-mode Rossby wave have height fields that are antisymmetric about the equator; Kelvin wave and the odd-mode Rossby waves have symmetric structures. We expect SST data to contain both symmetric and antisymmetric pieces. Let $T$ be the surface temperature, then we can decompose $T(x, y, t)$ into two parts:

$$
\begin{aligned}
T(x, y, t)=\frac{T(x, y, t)+T(x,-y, t)}{2} & \\
+ & +\frac{T(x, y, t)-T(x,-y, t)}{2}
\end{aligned}
$$

The first part is symmetric, and the second is antisymmetric about the equator. Prior to computing the Fourier transform, we calculate the symmetric and antisymmetric parts. From the latitudinal structure of the Yanai wave (Figure 2), the maximum $h(x, y, t)$ occurs at one Rossby deformation radius from the equator. For $c=1.67 \mathrm{~m} \mathrm{~s}^{-1}$ and $\beta=2.3 \times$ $10^{-11} \mathrm{~m}^{-1} \mathrm{~s}^{-1}$, this distance is approximately $270 \mathrm{~km}$ or about $3^{\circ}$; for the Kelvin wave, the maximum value of $h(x, y$, $t$ ) occurs at the equator. Hence to isolate the Yanai wave, we study the antisymmetric part where $y=3^{\circ} \mathrm{N}$ and $-y=$ $3^{\circ} \mathrm{S}$. This is done for the entire record, i.e., 2 years' data, and yields a new time series containing only antisymmetric information.

Similarly, we can also calculate the symmetric part. The time mean is removed from both parts of the time series at each spatial location.

The spectrum of antisymmetric component of SST data (Figure $3 a$ ) has been smoothed recursively using a hanning filter, with 11.4 degrees of freedom for each smoothed spectral estimate. A significant peak with a period centered near 26 days is evident. If we plot the spectrum in a variance-preserving form (Figure $3 b$ ), the sum of the area under the curve is equal to the total variance of the data. This plot clearly shows an energetic oscillation centered at

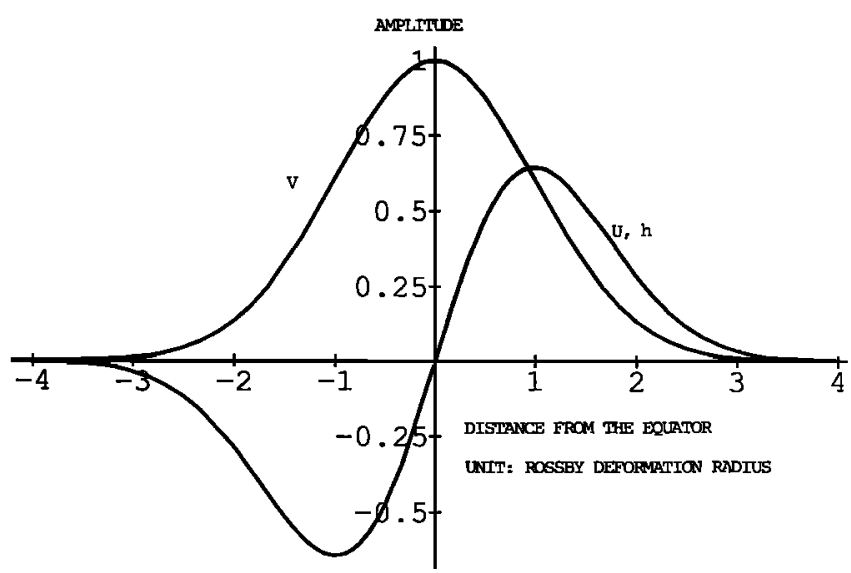

Fig. 2. Plot of the latitudinal structure of the Yanai wave. The scale on the horizontal axis is one Rossby deformation radius. We see that the maximum meridional velocity $v$ occurs at the equator, whereas the maximum height field $h$ and zonal velocity $u$ occur at one Rossby deformation radius from the equator.
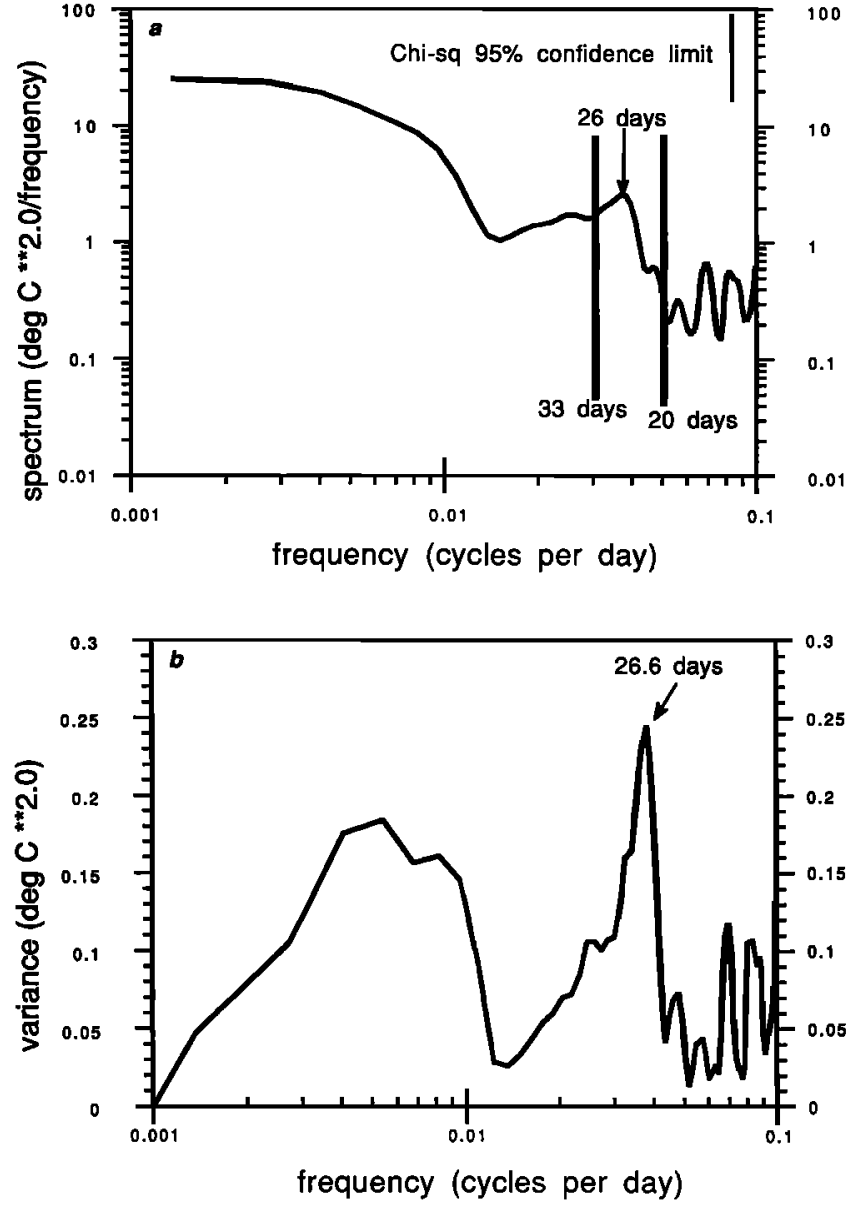

Fig. 3. (a) Spectrum of the antisymmetric component of SST data at $3^{\circ} \mathrm{N}$ and $56^{\circ} \mathrm{E}$. (b) Variance-preserving spectrum of the antisymmetric component of SST data at the same location as in Figure $3 a$.

the 26-day period. When compared with the spectrum of the symmetric component of SST data at the same location (Figure $4 a$ ), no significant peak is evident between frequencies of 0.03 to 0.05 cycles per day (33-day to 20 -day period). The variance-preserving energy spectrum of symmetric component (Figure $4 b$ ) shows that the most energetic oscillations have periods longer than 100 days, and relatively little energy is found in the frequency band of 0.03 to 0.05 cycles per day. This leads us to conclude that the fluctuation of the SST centered near the 26-day period is due predominantly to antisymmetric waves.

From the plot of the latitudinal structure of the Yanai wave (Figure 2), we see that the maximum $h$ displacement occurs near $3^{\circ}$ latitude and decreases poleward and toward the equator. We computed the spectrum for the antisymmetric part of SST at $5^{\circ}$ and $1^{\circ}$ to find out whether this 26-day oscillation shows a similar latitudinal dependence. The calculation shows that the variance near the 25 -day period at $5^{\circ}$ (Figure 5) is about $68 \%$ of the variance at $3^{\circ}$ with approximately the same period. The spectrum of the SST at $1^{\circ}$ (Figure 6) also shows a peak near 26 days. The variance associated with this frequency is about $29 \%$ of the variance at $3^{\circ}$ with the same frequency. This result agrees well with the theory. The energy of the 26-day oscillation decreases both north and south from $3^{\circ}$ and decreases at a faster rate 

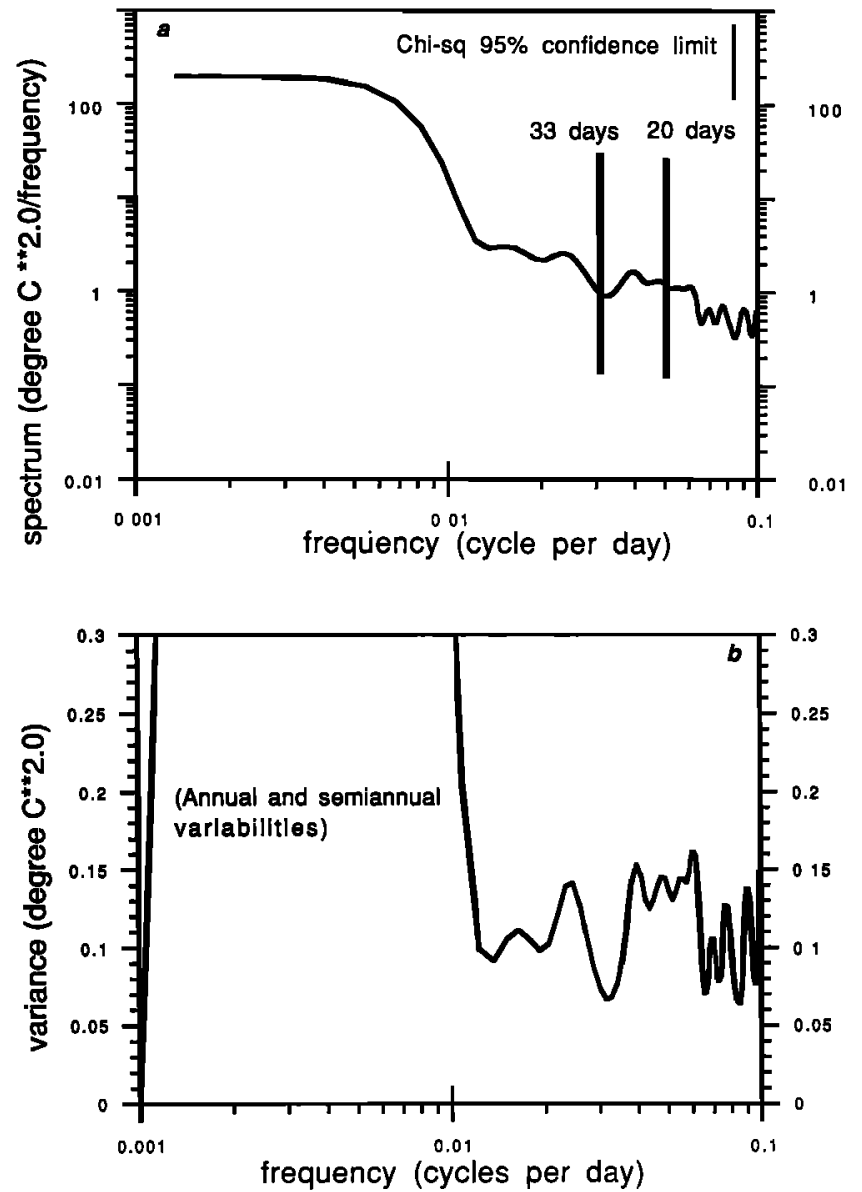

Fig. 4. (a) Spectrum of the symmetric component of SST data at $3^{\circ} \mathrm{N}$ and $56^{\circ} \mathrm{E} .(b)$ Variance-preserving spectrum of the symmetric component of SST at the same location as in Figure $4 a$.

toward the equator than poleward, which is consistent with the latitudinal structure of the Yanai wave (Figure 2).

In order to test further the latitudinal dependence of this 26-day oscillation, we assume that changes in height field $h(x, y, t)$ are coherent with changes in the SST. We can compute the available potential energy $E_{\text {pot }}$ of Yanai wave as a function of latitude. This is done by taking the average of the square of the height field $h(x, y, t)$ :

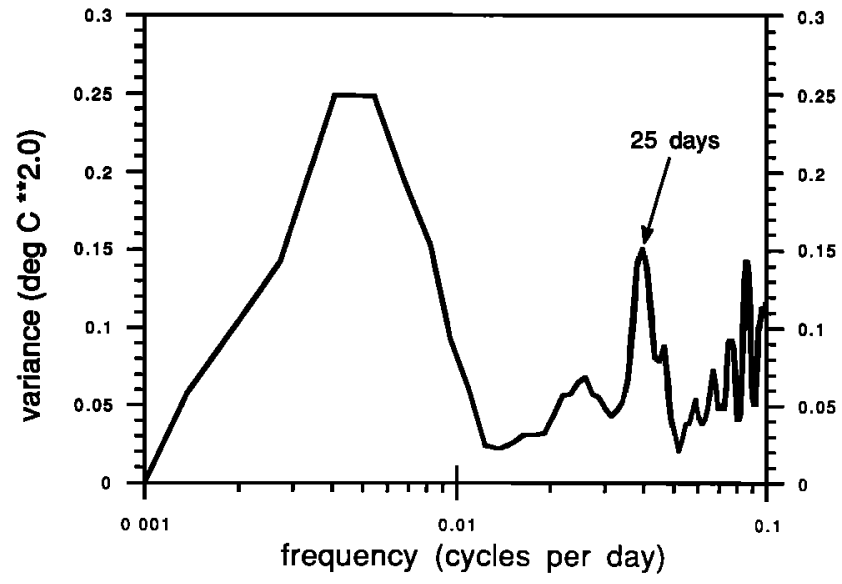

Fig. 5. Variance-preserving spectrum of the antisymmetric component of SST data at $5^{\circ} \mathrm{N}$ and $56^{\circ} \mathrm{E}$.

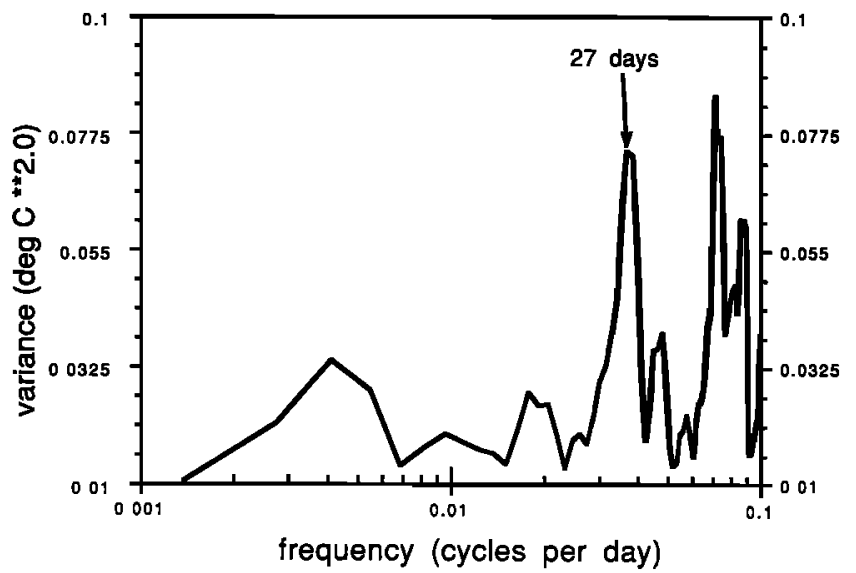

Fig. 6. Variance-preserving spectrum of the antisymmetric component of SST data at $1^{\circ} \mathrm{N}$ and $56^{\circ} \mathrm{E}$.

$$
E_{\text {pot }}=\frac{1}{2} \overline{h^{2}}
$$

assuming $h$ is sinusoidal in $x$ and $t$,

$$
\begin{aligned}
E_{\mathrm{pot}}=\frac{1}{2} & \frac{1}{T} \frac{1}{X} \int_{0}^{X} \int_{0}^{T} \cos ^{2}(\kappa x-\omega t) \psi_{1}^{2}(y) d x d t \\
& =\frac{1}{2} \frac{1}{T} \frac{1}{X} \psi_{1}^{2}(y) \int_{0}^{X} \int_{0}^{T} \frac{1+\cos 2(\kappa x-\omega t)}{2} d x d t
\end{aligned}
$$

Since we are integrating over one complete zonal wavelength and a period, the integral involving cosine term is then zero; thus

$$
E_{\mathrm{pot}}=\frac{1}{4} \frac{1}{T} \frac{1}{X} \psi_{1}^{2}(y) \int_{0}^{X} \int_{0}^{T} d x d t=\frac{1}{4} \psi_{1}^{2}(y)
$$

The circles in Figure 7 represent the variance accounted for by the 26-day oscillation in the antisymmetric component of the SST data from $1^{\circ}$ to $5^{\circ}$ latitude. The result shows that the latitudinal structure of the 26-day oscillation agrees quite well with that of the Yanai wave.

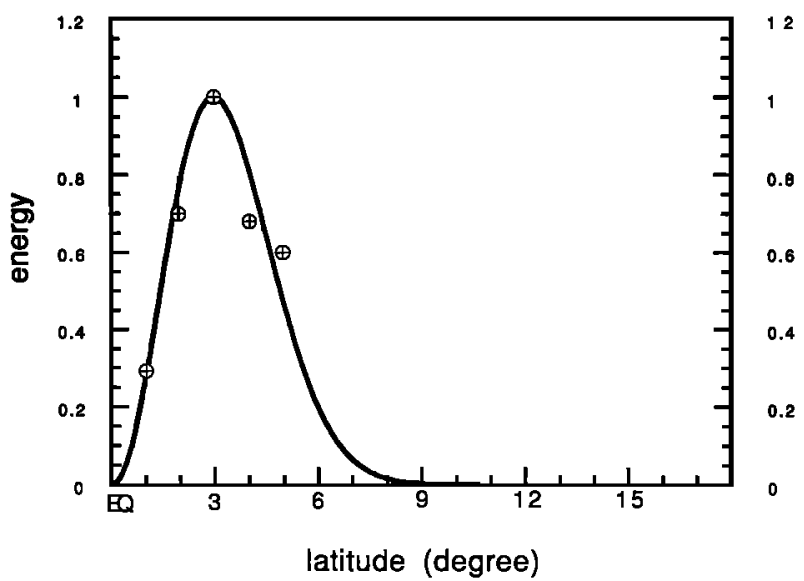

Fig. 7. Plot of the available potential energy of Yanai wave as predicted from the linear wave theory (solid line), and the observed variances (circles) of the 26-day oscillation in the antisymmetric component of SST data, both as a function of the latitude and with maximum values normalized to 1 . 


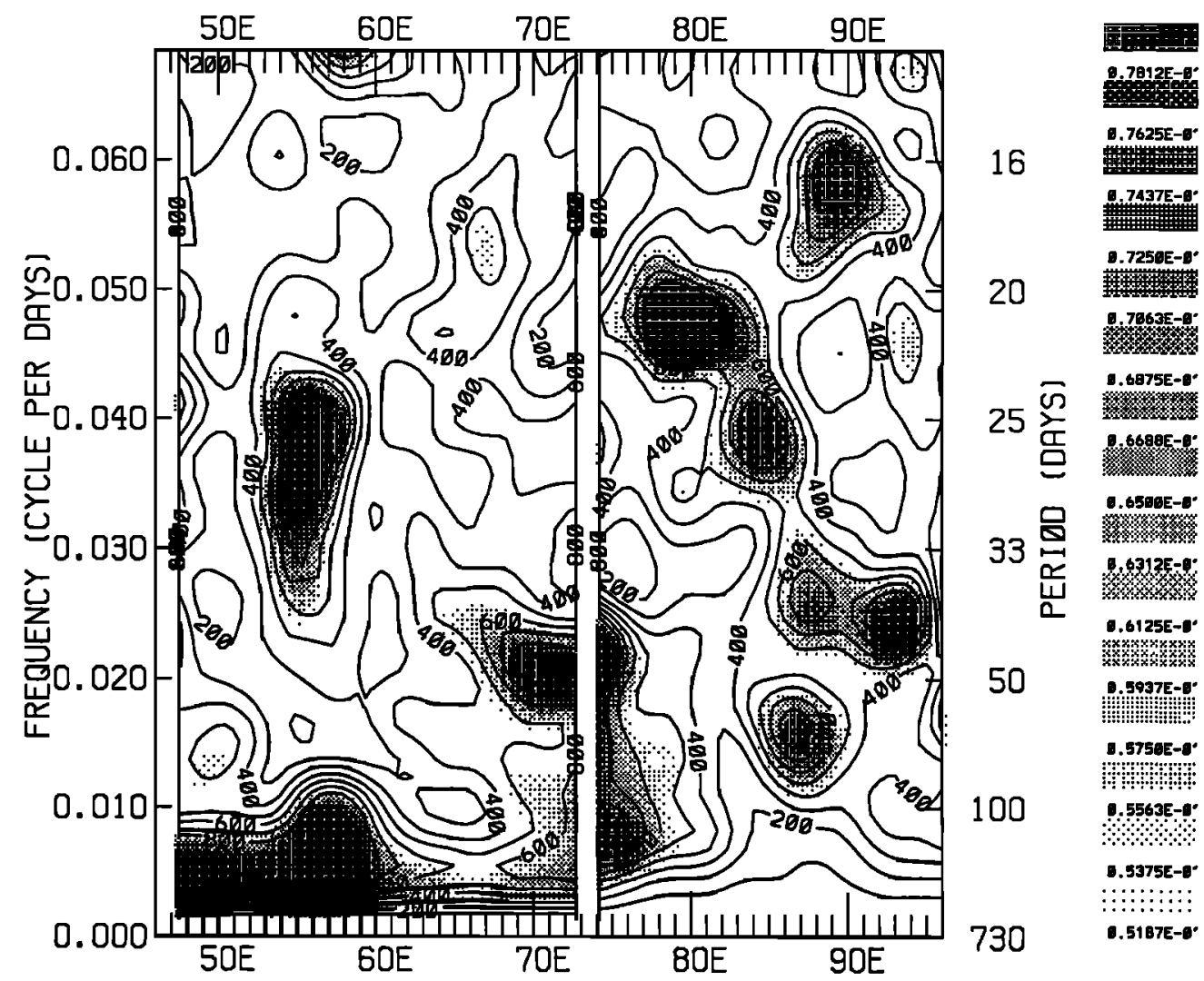

Fig. 8. Contour plot of the energy spectrum for the antisymmetric component of SST data at $3^{\circ}$ latitude, from $46^{\circ}$ to $96^{\circ} \mathrm{E}$. The contour levels represent the variances, and the horizontal and vertical axes represent the longitude and frequency (period), respectively. The contour levels have been scaled so the values of variance are between 200 to 800 , with each contour level representing an increment of 100 .

In summary, we have shown that there is a preferred oscillation in the SST data with a period of about 25-27 days. This oscillation is antisymmetric about the equator. From the dispersion diagram (Figure 1) and using scaling parameters typical of the Indian Ocean, i.e., $c=1.67 \mathrm{~m} \mathrm{~s}^{-1}$ [Moore and McCreary, 1990] and $\beta=2.3 \times 10^{-11} \mathrm{~m}^{-1} \mathrm{~s}^{-1}$, we see that the only possible antisymmetric wave between periods of $\mathbf{7}$ and $\mathbf{4 0}$ days is the Yanai wave. It is also unlikely that this 25- to 27-day oscillation is a result of direct atmospheric forcing, since the dominant periods of atmospheric oscillation in the equatorial region is of 40 to 60 days [Mertz and Mysak, 1984; Madden and Julian, 1972]. Finally, the variance associated with this $25-27$ days' oscillation has a latitudinal dependence that closely resembles the potential energy of the Yanai wave calculated from linear wave theory. All these results strongly suggest that the Yanai wave is responsible for the 25- to 27-day oscillation observed in the SST data.

\subsection{Zonal Variation}

In this section the zonal structure of the 26-day oscillations is investigated. The energy spectrum of the antisymmetric component of the SST data is computed at every half degree longitude increment from $46^{\circ}$ to $96^{\circ} \mathrm{E}$, with the latitude fixed at $3^{\circ}$. The variances of the contours in Figure 8 are smoothed in the zonal direction with two passes of a Hanning filter $(0.25,0.5,0.25)$.

The result (Figure 8) shows that in the western Indian Ocean, between longitudes $52^{\circ}$ and $60^{\circ} \mathrm{E}$, a region of strong spectral energy occurs between 23 and 33 days, with a peak centered near 26 days. This pocket of energy is associated with the 26-day Yanai wave previously mentioned. Another feature that stands out is the low-frequency energy (denoted by the variability with periods longer than 100 days) which can be seen to dominate across the western basin, with highest values found near the boundary with the coast of Africa. In the Bay of Bengal $\left(75^{\circ}\right.$ to $\left.95^{\circ} \mathrm{E}\right)$, this low-frequency energy is nowhere as dominant. This indicates that the annual and seasonal signals in the SST data, which contribute to the low-frequency variability, are more energetic in the western Indian Ocean, especially near the western boundary, than in the Bay of Bengal. This is consistent with the observation that monsoons in the western Indian Ocean are much stronger than the monsoons in the Bay of Bengal.

Numerical modeling results from Woodberry et al. [1989] indicate that the strongest signals of the Yanai waves are found between $50^{\circ}$ and $60^{\circ} \mathrm{E}$. From our data, it appears that the 26-day oscillation in SST data occurs only in the western Indian Ocean from $52^{\circ}$ to $60^{\circ} \mathrm{E}$. Farther away from the western boundary, this signal is not seen. This is reasonable because we expect other physical effects such as dissipation and advection and interference with the land barrier (Maldive Islands) to weaken the signal of this 26-day oscillation as it propagates eastwards away from the western boundary.

\subsection{Temporal Variation of the 26-day Oscillation in the $S S T$}

In this section the seasonal and interannual variability of the 26-day Yanai wave are investigated. The complex de- 


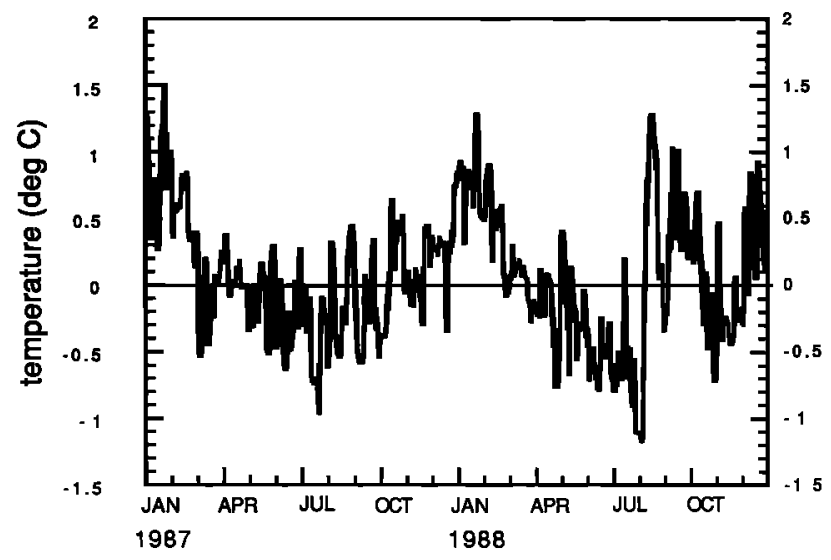

Fig. 9. Time series of the antisymmetric component of SST for 1987 and 1988 with $\Delta T=1$ day, at location $3^{\circ} \mathrm{N}$ and $56^{\circ} \mathrm{E}$.

modulation method is performed on the SST data at $3^{\circ}$ latitude and $56^{\circ} \mathrm{E}$ to obtain information on the time varying amplitude of this wave. This technique consists of multiplying the time series of the antisymmetric component of SST data (Figure 9) with $2 i \exp \left(i 2 \pi f_{0} t\right)$, where $f_{0}$ is the frequency of the Yanai wave ( $f_{0}=1 / 26$ days). The resulting complex time series is then low-pass filtered. The frequency response function of the low-pass filter used has a bandwidth of $0 \pm 5.1 \Delta f$ at the half power point ( $\Delta f$ is given by $1 /$ total length of the time series, in our case, $\Delta f=1 / 730$ days).

The resulting record (Figure 10) covers a time span of almost 2 years, with the beginning and the last 50 days of the time series lost as a result of the low-pass filtering. The plot represents the amplitude of the SST fluctuation caused by the 25- to 27-day oscillation as a function of time. On the average this amplitude is about $0.2^{\circ} \mathrm{C}$. We will choose this value as the level of the background noise in the data. Figure 10 shows that amplitude of this 25 - to 27 -day oscillation in the sea surface temperature data is the largest during the summer monsoon (July, August, and September), with values of $0.4^{\circ}$ and $0.8^{\circ} \mathrm{C}$ found in August of 1987 and 1988 respectively. For most of the winter monsoon, this amplitude drops below the noise level (January to March 1988), with the only exceptions being the two smaller peaks of

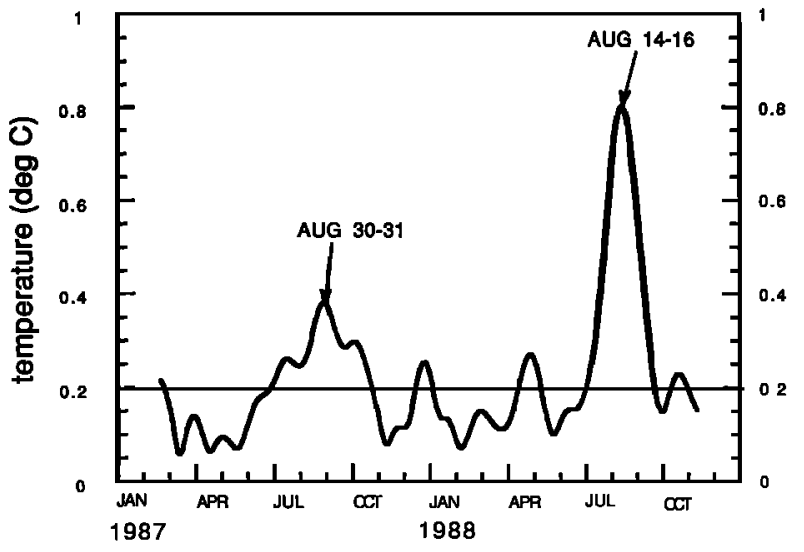

Fig. 10. Plot of the complex demodulated SST time series at location $3^{\circ}$ latitude and $56^{\circ} \mathrm{E}$. It represents the time-varying amplitude of the 26-day fluctuation in sea surface temperature measurement over a 2-year period. This amplitude is the largest during the summer, with the maximum value occurring in August. approximately $0.25^{\circ} \mathrm{C}$ observed in December 1987 and April 1988. During the transitional periods between summer and winter monsoon, i.e., from March to May and from late October to November 1987, and then again from May to June 1988, amplitudes of this 26-day oscillation are also below the noise level.

Although the length of SST time series used in this study is not long enough to adequately assess the recurrence of the same feature in the seasonal cycle and the effect of the interannual variability, some of the features are nevertheless well defined. These variabilities can be summarized in the following: the activity of the 26-day Yanai wave observed at $3^{\circ}$ latitude and $56^{\circ} \mathrm{E}$ is the strongest during the summer (July-September) of both years, very weak and sometimes not observed in late winter/spring months (January-March), and virtually not detected at all during the transitional months between monsoons (May-June and OctoberNovember). (At the time when this analysis was done, only 2 years of SST data were available to the authors. As more SST data become available, it will be of interest to see if temporal variabilities observed in the present study also exist in longer time series.)

Reverdin and Luyten [1986] investigated the data obtained from the drifting buoys that were released along the equator in the western Indian Ocean between $50^{\circ} \mathrm{E}$ and $60^{\circ} \mathrm{E}$ from 1979 to 1982 . It was found that these buoys exhibited meridional oscillatory motions at a period close to 25 days while drifting eastward, with meridional displacement of $\geq 300 \mathrm{~km}$ and meridional velocity of $0.8 \mathrm{~m} \mathrm{~s}^{-1}$. During the same time, fluctuations in the mixed layer depth of more than $15 \mathrm{~m}$ at a period of 25 days as well as SST changes of $\leq 1{ }^{\circ} \mathrm{C}$ were also observed. Other characteristics associated with this meandering motion are that energy in the meridional velocity component significantly exceeds the energy in the zonal velocity, the phase difference between $u$ and $v$ is one-half period, and lagged correlation suggests that these meanders are moving westward with a phase speed of $\mathbf{4 0 \pm}$ $15 \mathrm{~cm} \mathrm{~s}^{-1}$. All these characteristics suggest that the oscillatory motions observed in drifting buoys are a result of Yanai waves. An interesting observation made by Reverdin and Luyten [1986] on these 25-day meanders was that they were found only during August-September of 1979, 1980, and 1981. After October the meandering still persisted but at a small amplitude and at a period of about 12 days. No meandering was found from January to March. Since our data are for 1987 and 1988, direct comparisons are not possible. However, the dominant features of the seasonal variability found in the data, namely, the strong 26-day oscillations during July-September, little or no oscillation in October-November and also from January to March, are quite consistent with their findings.

In the model simulation of the Indian Ocean by Kindle and Thompson [1989], intense 26-day Yanai wave packets are initially formed within $1400 \mathrm{~km}$ of the western boundary during July. Subsequently, these wave packets propagate eastward, with group speed of 0.24 to $0.46 \mathrm{~m} \mathrm{~s}^{-1}$, and become evident near $55^{\circ} \mathrm{E}$ in August. During the northeast monsoon, from November to March, the Yanai waves are not as intense as those generated during the summer monsoon, nor do they propagated as far eastward. In the model simulation by Woodberry et al. [1989], Yanai wave packets can also be seen emanating from the western boundary region on the time versus longitude plot of meridional 
transport across the equator. These waves have a period of 28 days with a westward phase propagation and an eastward group velocity. The strongest and most coherent signals of these Yanai wave packets are seen in the region between $50^{\circ}$ and $65^{\circ} \mathrm{E}$, from July to September. Thus, the observed temporal variations from the SST data are consistent with the modeling results of the Indian Ocean.

\section{Summary and Conclusions}

A 26-day oscillation was observed in the SST data obtained from the NOAA 9 satellite. The signal of this oscillation is trapped within $6^{\circ}$ latitude of the equator and between $52^{\circ}$ and $60^{\circ} \mathrm{E}$. The structure of this oscillation is found to be antisymmetric. The variance associated with this 26-day oscillation is a maximum at a distance about $3^{\circ}$ latitude from the equator. This variance decreases away from $3^{\circ}$ at a faster rate toward the equator than toward the poles. By assuming a coherent relationship between the fluctuations in the SST and the changes in the mixed layer thickness, we have shown that the variance accounted for by this 26-day oscillation exhibits a latitudinal structure that is very similar to that of the available potential energy of the Yanai wave as predicted by the linear wave theory. The location where these 26-day oscillations are observed in the SST data is also near the location where Luyten and Roemmich [1982] found the 26-day oscillation in the meridional velocity in the upper $200 \mathrm{~m}$.

The amplitude of this 26-day oscillation in the SST data is found to be the largest during the summer season (July to September), with a maximum amplitude of $0.4^{\circ} \mathrm{C}$ in August of 1987 and $0.8^{\circ} \mathrm{C}$ in August of 1988 . This observation is consistent with the temporal variability of the Yanai wave as seen in the modeling results of the Indian Ocean by Kindle and Thompson [1989] and by Woodberry et al. [1989]. Furthermore, it is also consistent with the strong 25-day meridional meanders observed in the drifting buoys during the summer seasons, which is believed to be a result of Yanai waves [Reverdin and Luyten, 1986].

These characteristics described above, namely, the observed temporal variation, the latitudinal structure, the 25 to 27-day period, and the location, strongly suggest that this oscillation in the SST data is due to the motion of Yanai waves.

One interesting question is why the period of this Yanai wave is $\mathbf{2 6}$ days. In the linear, continuously stratified model used by Moore and McCreary [1990], Yanai waves with a period of $\mathbf{3 0}$ days are generated when the model is forced with a oscillatory wind stress of the same period. However in both numerical simulations of the Indian Ocean, by Kindle and Thompson [1989], and by Luther and O'Brien [Woodberry et al., 1989], monthly wind stress is used to force the models. The shortest resolvable period in the wind fields in both models is 60 days; nevertheless Yanai waves with periods of 26-28 days are observed. This suggests that the period of Yanai waves is an oceanic response and is not directly due to atmospheric forcing at a 26-day period. The exact nature of this oceanic response is an area for future investigation.

\section{APPENDIX}

The $u, v$, and $h$ of the inertia-gravity waves and the Rossby waves are given by the following, with subscript $m$ representing the different horizontal modes:

$$
\begin{gathered}
v_{m}=\exp (i \kappa x-i \omega t) y_{m}(y) \\
u_{m}=\frac{i}{2} \exp (i \kappa x-i \omega t)\left[\frac{(2 m)^{1 / 2} y_{m-1}}{\kappa+\omega}\right. \\
\left.+\frac{\left.[2(m+1)]^{1 / 2} y_{m+1}\right]}{\omega-\kappa}\right] \quad m=1,2,3, \cdots \\
h_{m}=\frac{i}{2} \exp (i \kappa x-i \omega t)\left[\frac{[2(m+1)]^{1 / 2} y_{m+1}}{\omega-k}-\frac{(2 m)^{1 / 2} y_{m-1}}{\kappa+\omega}\right]
\end{gathered}
$$

where $y_{m}(y)$ is the Hermite function given by

$$
y_{m}(y)=\frac{\exp \left(-y^{2} / 2\right) H_{m}(y)}{\left(2^{m} m ! \pi^{1 / 2}\right)^{1 / 2}} \quad m=0,1,2,3, \cdots
$$

and where $H_{m}(y)$, the Hermite polynomials, are given by

$$
H_{0}=1, H_{1}=2 y, H_{2}=4 y^{2}-2, H_{3}=8 y^{3}-12 y, \cdots
$$

Acknowledgments. This research was supported by the Physical Oceanography Program of the Office of Naval Research, Physical Oceanography and Climate Dynamics Sections of the National Science Foundation and the Oceanic Processes Branch of NASA. We are particularly appreciative of the SST data supplied by Richard Legeckis, NOAA, NESDIS. In addition, Alan Davis' assistance on the computer is very helpful. The computer time was supplied by the FSU Computing Center.

\section{REFERENCES}

Brown, O. B., J. G. Bruce, and R. H. Evans, Evolution of sea surface temperature in the Somali Basin during the southwest monsoon of 1979, Science, 209, 595-597, 1980.

Bruce, J. G., Eddies off the Somali coast during the southwest monsoon, J. Geophys. Res., 84(C12), 7742-7748, 1979.

Evans, R. H., and O. B. Brown, Propagation of thermal fronts in the Somali Current system, Deep Sea Res., 28, 521-527, 1981.

Hastenrath, S., and P. Lamb, Climatic Atlas of the Indian Ocean, vol. 1, University of Wisconsin Press, Madison, 1979.

Hellerman, S., and M. Rosenstein, Normal monthly wind stress over the world ocean with error estimates, J. Phys. Oceanogr., $13,1093-1104,1983$.

Hurlburt, H. E., J. C. Kindle, and J. J. O'Brien, A numerical simulation of the onset of El Niño, J. Phys. Oceanogr., 6, $621-631,1976$.

Kindle, J. C., and J. D. Thompson, The 26- and 50-day oscillations in the western Indian Ocean: Model results, J. Geophys. Res., 94(C4), 4721-4736, 1989.

Knox, R. A., The Indian Ocean: Interaction with the monsoon, in Monsoons, edited by J. S. Fein and P. L. Stephens, pp. 365-397, John Wiley, New York, 1987.

Knox, R. A., and D. Halpern, Long range Kelvin wave propagation of transport variations in Pacific Ocean equatorial currents, $J$. Mar. Res., 40, suppl., 329-339, 1982.

Leetmaa, A., D. R. Quadfasel, and D. Wilson, Development of the flow field during the onset of the Somali Current, J. Phys. Oceanogr., 12, 1325-1342, 1982.

Legeckis, R., Long waves in the eastern equatorial Pacific Ocean: A view from a geostationary satellite, Science, 197, 1197-1181, 1977.

Luther, D. S., Observations of long period waves in the tropical oceans and atmosphere, Ph.D. thesis, MIT-WHOI Joint Program in Oceanography, Woods Hole, Mass., 1980.

Luther, M. E., J. J. O'Brien, and A. H. Meng, Morphology of the Somali Current system during the southwest monsoon, in Coupled Ocean-Atmosphere Models, edited by J. C. J. Nihoul, pp. 405-437, Elsevier, New York, 1985.

Luyten, J. R., and D. H. Roemmich, Equatorial currents at semiannual period in the Indian Ocean, J. Phys. Oceanogr., 12, $406-413,1982$. 
Madden, R. A., and P. R. Julian, Description of global-scale circulations cells in the tropics with a 40-50 day period, J. Atmos. Sci., 29, 1109-1123, 1972.

Matsuno, T., Quasi-geostrophic motions in equatorial areas, $J$. Meteorol. Soc. Jpn., 2, 25-43, 1966.

McClain, E. P., W. G. Pichel, and C. C. Walton, Comparative performance of AVHRR-based multichannel sea surface temperatures, J. Geophys. Res., 90(C6), 11,587-11,601, 1985.

McCreary, J. P., and P. K. Kundu, A numerical investigation of sea surface temperature variability in the Arabian Sea, J. Geophys. Res., 94(C11), 16,097-16,114, 1989.

McMillin, L. M., and D. S. Crosby, Theory and validation of the multiple window sea surface temperature technique, J. Geophys. Res., 89(C3), 3655-3661, 1984.

Mertz, G. J., and L. A. Mysak, Evidence for a 40-60 days oscillation over the western Indian Ocean during 1976 and 1979, Mon. Weather Rev., 112, 383-386, 1984.

Moore, D. W., Planetary-gravity waves in an equatorial ocean, Ph.D. thesis, Harvard Univ., Cambridge, Mass., 1968.

Moore, D. W., and J. P. McCreary, Excitation of intermediatefrequency equatorial waves at a western ocean boundary: With application to observations from the Indian Ocean, J. Geophys. Res., 95(C4), 5219-5231, 1990.

Moore, D. W., and S. G. H. Philander, Modeling of the tropical oceanic circulation, in The Sea: Ideas and Observations on Progress in the Study of the Seas, vol. 6, edited by E. Goldberg et al., pp. 319-361, John Wiley, New York, 1977.
Reverdin, G., and J. Luyten, Near-surface meanders in the equatorial Indian Ocean, J. Phys. Oceanogr., I6, 1088-1100, 1986.

Schott, F., Monsoon response of the Somali Current and associated upwelling, Prog. Oceanogr., 12, 357-382, 1983.

Swallow, J. C., R. L. Molinari, J. G. Bruce, O. B. Brown, and R. H. Evans, Development of near-surface flow pattern and water mass distribution in the Somali Basin, in response to the southwest monsoon of 1979, J. Phys. Oceanogr., 13, 1398-1415, 1983.

Woodberry, K. E., M. E. Luther, and J. J. O'Brien, The winddriven seasonal circulation in the southern tropical Indian Ocean, J. Geophys. Res., 94(C12), 17,985-18,002, 1989.

Wunsch, C., and A. E. Gill, Observations of equatorially trapped waves in Pacific sea level variations, Deep Sea Res., 23, 371-390, 1976.

M. E. Luther, Department of Marine Science, University of South Florida, St. Petersburg, FL 33701.

J. J. O'Brien, Mesoscale Air-Sea Interaction Group, Mail Stop B-174, Love 012, Florida State University, Tallahassee, FL 32306.

P. T. H. Tsai, Code OC/TS, Department of Oceanography, Naval Postgraduate School, Monterey, CA 93943.

(Received January 7, 1991; revised July 8,1991 ; accepted July 9, 1991.) 